\title{
Outcomes of thyroid operations in patients of different age
} groups

\author{
Ali Çiftçi1 ${ }^{1}$, Çağrı Tiryaki²® \\ ${ }^{1}$ Department of General Surgery, University of Health Sciences, Kocaeli Derince Training and Research Hospital, Kocaeli, Turkey \\ ${ }^{2}$ Department of General Surgery, Buhara Hospital, Erzurum, Turkey
}

\section{ABSTRACT}

Objectives: To determine the effects of age on preoperative findings and on outcomes of thyroid surgeries. Methods: In this retrospective study, we analyzed the demographics, surgical and pathological data, postoperative complications and biochemical results including calcium, phosphorus and parathyroid hormone (PTH) levels of patients who undertaken thyroid operations.

Results: Totally 288 consecutive patients operated for thyroid diseases were included in the study. The patients were grouped regarding their ages as patients in the $3^{\text {rd }}$ decade $(n=26), 4^{\text {th }}$ decade $(n=60), 5^{\text {th }}$ decade $(n=$ $81), 6^{\text {th }}$ decade $(n=77)$ and $7^{\text {th }}$ decade $(n=44)$. There was not any significant difference between groups regarding the preoperative diagnoses $(p=0.09)$. With an advance in age, the presence of multiple nodules in preoperative period was increasing $(p=0.015)$. On postoperative period, the pathological diagnosis was malignant in $46(15.9 \%)$ patients. There was not any significant difference between groups regarding the tumor type $(p=0.80)$. The most common tumor type was papillary carcinoma in all age groups. Postoperative complications were determined in $68(23.6 \%)$ patients and there was not any significant difference regarding the presence of postoperative complications in all age groups $(p=0.26)$.

Conclusions: In conclusion, there was not any significant difference regarding postoperative outcomes in patients operated for thyroid diseases who were in the different decades of their lives. We can suggest that, thyroid surgeries are as safe in elderly patients as in younger patients.

Keywords: thyroid surgery, age, complications

$\mathrm{T}$ he incidence of thyroid diseases, especially cancers requiring surgery is increasing every day, most probably with the advances in diagnostic methods $[1,2]$. Thyroidectomy is the most commonly performed endocrine surgery and for that reason, the patients requiring surgical treatment for thyroid diseases at different age groups are also augmenting [3].

Although thyroid surgeries are reported to have low rates of mortality and morbidity with advances in surgical techniques; in clinical practice, it was reported that, especially elderly patients with some thyroid dis- eases are less likely to receive specified therapies [4$6]$.

In this study, we aimed to determine the effects of age on preoperative findings and on outcomes of thyroid surgeries.

\section{METHODS}

In this retrospective study, we analyzed the demographics, surgical and pathological data, postoperative 
complications and biochemical results including calcium, phosphorus and parathyroid hormone (PTH) levels of patients who undertaken thyroid operations between 2010 and 2017 in the University of Health Sciences, Kocaeli Derince Training and Research Hospital. The hospital records of patients operated for any thyroid diseases were retrospectively investigated and patients with missing records were not included in the study. The patients were grouped into decades regarding their ages to determine the effects of age on outcomes of thyroid operations. The indications for thyroid surgeries, preoperative ultrasonographic findings, the results of fine needle aspiration biopsy (FNAB) in preoperative period if present; histological findings, complications and laboratory data after operation were recorded. All surgeries were performed by the same operation team. Ethical committee approval was not obtained because the study was done retrospectively by evaluation of patients' data's.

\section{Statistical Analysis}

The data analysis was performed using the Statistical Package for the Social Sciences for Windows version 21.0 (SPSS Inc.; Chicago, IL, USA). Regarding descriptive statistics, the categorical variables were expressed as number and percentage and the numerical variables were expressed as mean, and standard deviation. In comparison of categorical variables, Chisquare test was performed. The numerical data were compared with the one way ANOVA. A $p<0.05$ was considered statistically significant.

\section{RESULTS}

In this study, we analyzed the general characteristics and outcomes of 288 consecutive patients operated for thyroid diseases regarding their ages (Table 1). Concurrent parathyroid operations were performed in $13(4.5 \%)$ patients. Among study participants, 247 $(85.7 \%)$ were female but there was not any significant difference regarding gender between patients at different decades during operation $(p=0.77)$. Preoperative indication was analyzed in all decades. There was not any significant difference between groups regarding the preoperative diagnoses $(p=0.09)$. Number of nodules in preoperative period was significantly different between groups $(p=0.015)$. With an advance in age, the presence of multiple nodules was increasing.

In preoperative period, the suspicion of neoplasm was present in 42 patients while in postoperative period, the pathological diagnosis was malignant in 46 $(15.9 \%)$ patients. There was not any significant difference between groups regarding the tumor type ( $p=$ $0.80)$. The most common tumor type was papillary carcinoma in all age groups. Substernal goiter was significantly more common in the 6th decade $(p=0.01)$. Location of tumor was significantly more commonly right lobe in patients in the $5^{\text {th }}$ decade while it was significantly more commonly left lobe in patients in the $7^{\text {th }}$ decade $(p=0.009)$. There was not any significant difference regarding the presence of postoperative complications in all age groups $(p=0.26)$.

In preoperative period, 14 patients were diagnosed with atypia with undefined significance and the postoperative diagnosis of these patients were papillary carcinoma $(n=3)$, follicular adenoma $(n=2)$, nodular goutier $(n=7)$, hurtle cell carcinoma $(n=1)$ and granulomatous thyroiditis $(\mathrm{n}=1)$. On the other hand, fine needle aspiration biopsy (FNAB) was performed to the 34 of the patients diagnosed with any type of carcinomas in postoperative period. The results of those FNAB were as follows; adenomatous hyperplasia ( $n$ $=9)$, follicular neoplasm $(\mathrm{n}=1)$, hyperplastic colloid nodule $(n=2)$, papillary carcinoma $(n=10)$, atypia with undefined significance $(n=3)$, hurtle cell carcinoma $(\mathrm{n}=3)$, degenerated nodule $(\mathrm{n}=1)$ in papillary carcinoma group; follicular neoplasia $(n=2)$ in follicular carcinoma group; and hurtle cell neoplasm ( $\mathrm{n}=$ 2 ) in hurtle cell carcinoma group.

Bilateral total thyroidectomy was the most commonly performed operation in all age groups (Table 2 ). Right lobectomy + isthmectomy was significantly more commonly performed in patients in the $3^{\text {rd }}$ decade compared with other age groups. Neck dissection was performed in 15 patients and there was not any significant difference between groups regarding the requirement of neck dissection.

There was not any significant difference regarding the presence of postoperative complications between groups. Transient hypocalcaemia was more common in patients in the $5^{\text {th }}$ decade. (Table 3 ).

In postoperative period, calcium, phosphorus and parathyroid hormone levels were compared between groups (Table 4) and PTH levels were determined to be significantly higher in patients in the $6^{\text {th }}$ and $7^{\text {th }}$ 


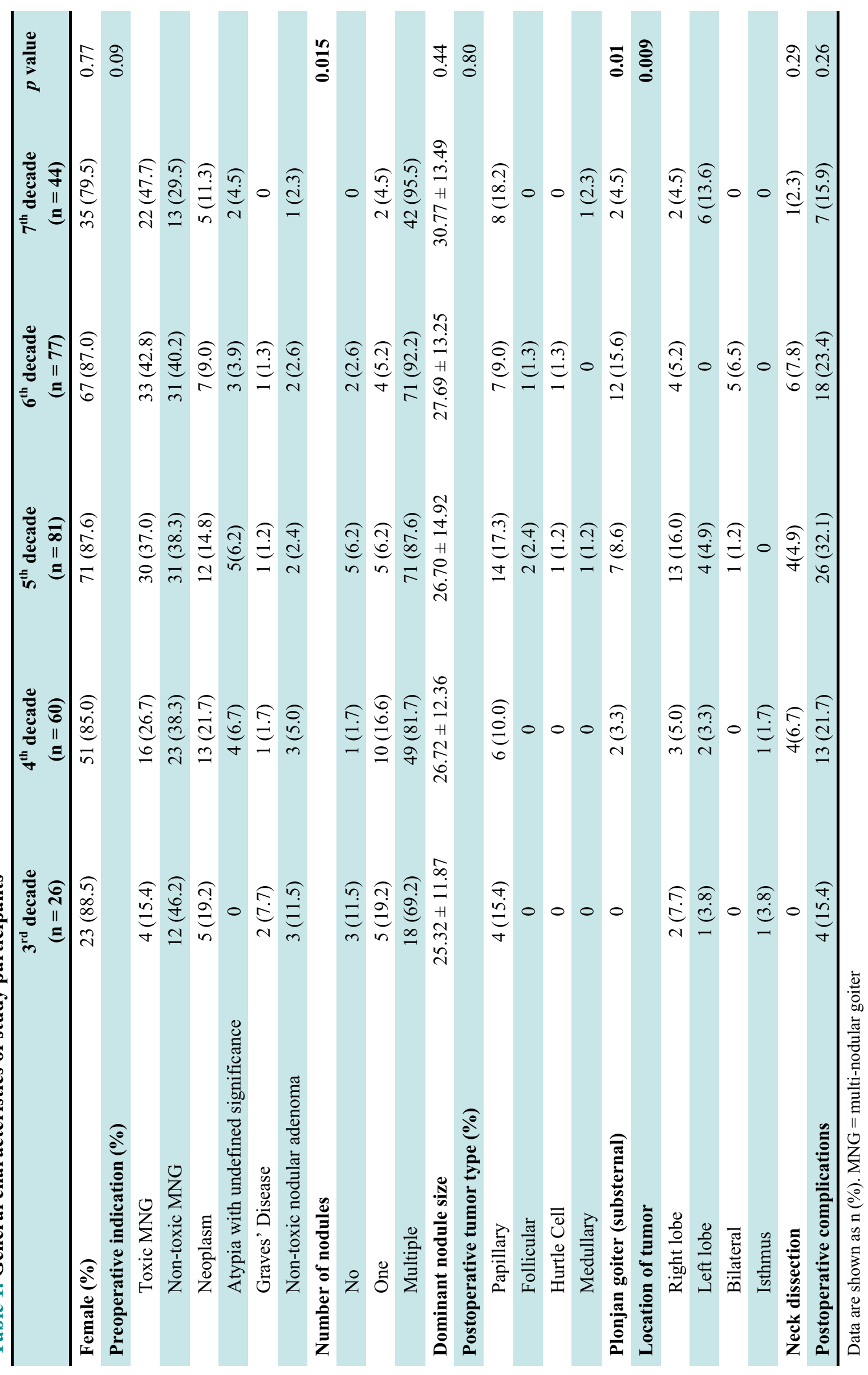


Table 2. Operation type

\begin{tabular}{lcccccc}
\hline & $\begin{array}{c}3^{\text {rd }} \\
(\mathbf{n}=\mathbf{2 6})\end{array}$ & $\begin{array}{c}\mathbf{4}^{\text {th }} \text { decade } \\
(\mathbf{n}=\mathbf{6 0})\end{array}$ & $\begin{array}{c}\mathbf{5}^{\text {th }} \text { decade } \\
(\mathbf{n}=\mathbf{8 1})\end{array}$ & $\begin{array}{c}\mathbf{6}^{\text {th }} \text { decade } \\
(\mathbf{n}=\mathbf{7 7})\end{array}$ & $\begin{array}{c}\mathbf{7}^{\text {th }} \text { decade } \\
(\mathbf{n}=\mathbf{4 4})\end{array}$ & $\boldsymbol{p}$ value \\
\hline $\begin{array}{l}\text { Right lobectomy } \\
+ \text { Isthmectomy }\end{array}$ & $6(23.1)$ & $7(11.7)$ & $6(7.4)$ & $1(1.3)$ & $1(2.3)$ & $\mathbf{0 . 0 1 1}$ \\
$\begin{array}{l}\text { Left lobectomy } \\
\text { +Isthmectomy }\end{array}$ & $1(3.8)$ & $5(8.3)$ & $3(3.7)$ & $1(1.3)$ & 0 & \\
$\begin{array}{l}\text { Bilateral total } \\
\text { thyroidectomy }\end{array}$ & $18(69.2)$ & $46(76.7)$ & $72(88.9)$ & $74(96.1)$ & $40(90.9)$ & \\
$\begin{array}{l}\text { Right total left near } \\
\text { total thyroidectomy }\end{array}$ & $1(3.8)$ & $2(3.3)$ & 0 & $1(1.3)$ & $1(2.3)$ & \\
\hline $\begin{array}{l}\text { Left total right near } \\
\text { total thyroidectomy }\end{array}$ & 0 & 0 & 0 & 0 & $2(4.5)$ & \\
\hline
\end{tabular}

Data are shown as $\mathrm{n}(\%)$.

Table 3. Postoperative complications

\begin{tabular}{lccccc}
\hline & $\begin{array}{c}3^{\text {rd }} \text { decade } \\
(\mathbf{n}=\mathbf{2 6})\end{array}$ & $\begin{array}{c}\mathbf{4}^{\text {th }} \text { decade } \\
(\mathbf{n = 6 0 )}\end{array}$ & $\begin{array}{c}\mathbf{5}^{\text {th }} \text { decade } \\
(\mathbf{n}=\mathbf{8 1})\end{array}$ & $\begin{array}{c}\mathbf{6}^{\text {th }} \text { decade } \\
(\mathbf{n}=\mathbf{7 7})\end{array}$ & $\begin{array}{c}\mathbf{7}^{\text {th }} \text { decade } \\
(\mathbf{n}=\mathbf{4 4})\end{array}$ \\
\hline Transient hypocalcemia (\%) & $1(3.8)$ & $8(13.3)$ & $18(22.2)$ & $8(10.4)$ & $5(11.4)$ \\
Hematoma (\%) & $1(3.8)$ & 0 & 0 & 0 & 0 \\
Wound Infection (\%) & $1(3.8)$ & $1(1.7)$ & $2(2.4)$ & $1(1.3)$ & 0 \\
Transient RLN paralysis (\%) & 0 & $1(1.7)$ & $3(3.7)$ & $3(3.9)$ & 0 \\
Permanent RLN paralysis (\%) & 0 & 0 & $1(1.2)$ & $2(2.6)$ & 0 \\
Trachea injury (\%) & 0 & 0 & 0 & $1(1.3)$ & $2(4.5)$ \\
Permanent hypocalcemia (\%) & $1(3.8)$ & $2(3.3)$ & $2(2.4)$ & $3(3.9)$ & 0 \\
Esophagus injury (\%) & 0 & $1(1.7)$ & 0 & 0 & 0 \\
\hline
\end{tabular}

Data are shown as $\mathrm{n}(\%)$.

decade compared with the younger patients while there was not any significant difference in postoperative calcium or phosphorus levels.

\section{DISCUSSION}

In this study, we analyzed the general characteristics of patients who were operated for any type of thyroid diseases and determined that most of the patients were female at all age groups; there was not any significant difference regarding the preoperative diagnoses between different age groups; with an advance in age, presence of multiple nodules was increasing. The pathological diagnosis was malignant in 46 $(15.9 \%)$ patients and there was not any significant dif- ference regarding the tumor type between patients at different age groups. The most common tumor type was papillary carcinoma in all age groups. Interestingly, substernal goiter was significantly more commonly determined in patients in the 6th decade. There was not any significant difference regarding the presence of postoperative complications in different age groups.

The data about the thyroid surgeries is accumulating in recent literature with an increase in the incidence of thyroid diseases [7-9]. In a retrospective study Grubey et al. [10] reported that, among 1207 outpatient thyroidectomy operations; $85.2 \%$ of the patients were female. They reported that there was not any significant difference between patients aged between 21 and 40 years, patients $>65$ years and patients 
Table 4. Postoperative calcium, phosphorus and parathyroid hormone levels

\begin{tabular}{lcccccc}
\hline & $\begin{array}{c}3^{\text {rd }} \text { decade } \\
(\mathbf{n = 2 6})\end{array}$ & $\begin{array}{c}\mathbf{4}^{\text {th }} \text { decade } \\
(\mathbf{n}=\mathbf{6 0})\end{array}$ & $\begin{array}{c}\mathbf{5}^{\text {th }} \text { decade } \\
(\mathbf{n}=\mathbf{8 1})\end{array}$ & $\begin{array}{c}\mathbf{6}^{\text {th }} \text { decade } \\
(\mathbf{n}=\mathbf{7 7})\end{array}$ & $\begin{array}{c}\mathbf{7}^{\text {th }} \text { decade } \\
(\mathbf{n}=\mathbf{4 4})\end{array}$ & $\boldsymbol{p}$ value \\
\hline Calcium & $8.42 \pm 0.63$ & $8.22 \pm 0.63$ & $8.30 \pm 0.64$ & $8.42 \pm 0.62$ & $8.41 \pm 0.63$ & 0.32 \\
Phosphorus & $3.73 \pm 0.74$ & $3.87 \pm 0.76$ & $4.10 \pm 0.79$ & $4.03 \pm 0.76$ & $3.91 \pm 0.83$ & 0.16 \\
PTH & $40.73 \pm 29.75$ & $41.32 \pm 31.78$ & $40.08 \pm 31.45$ & $54.91 \pm 36.24$ & $54.77 \pm 42.25$ & $\mathbf{0 . 0 2}$ \\
\hline
\end{tabular}

Data are shown as mean \pm standard deviation. $\mathrm{PTH}=$ Parathyroid hormone

$>80$ years regarding the complication and re-admission rates. Kovacic and Kovacic [11] investigated the outcomes of thyroid surgeries in 183 elderly patients and reported that patients $\geq 70$ years of age were having higher rates of malignant diseases. However they also reported that the complication rates were not high after thyroid surgeries in those patients with $\geq 65$ years of age. Similarly, Diaconescu et al. [12] also reported that despite some additional risks related to comorbidities in patients over 65 years, patients may benefit of all types of conservative or radical thyroidectomies. Canonico et al. [13] also reported that age did not increase the incidence of worse outcomes in patients who underwent thyroid surgery. On the other hand, in a population-based study on patients who underwent surgery for thyroid neoplasms, the rate of general postoperative complications was $6.5 \%$ and the rate of thyroid surgery-specific complications was $12.3 \%$. In that study, the authors determined that older age and more comorbidities were risk factors for postoperative complications [14]. Caulley et al. [15] reported that the 30day complication rate for total thyroidectomies was $7.74 \%$ and age $\geq 70$ was a risk factor for postoperative complications. Similarly Liu et al. [16] also determined that older age was a risk factor for post-thyroidectomy bleeding in their meta-analysis. In our study, we did not determine any significant difference regarding postoperative complication rates in patients at different age groups. Postoperative hematoma was determined in only one patient and she was 26 years old.

The most common complication reported after thyroid surgeries is transient hypocalcaemia which may be seen in as much as $70 \%$ of patients, while permanent hypocalcaemia is exceedingly rare [17]. In our study, the most common complication was also transient hypocalcaemia determined in $40(13.9 \%)$ patients while permanent hypocalcaemia was determined in only $8(2.7 \%)$ patients.

The most common indications for thyroid surgeries include goitre, Grave's disease, toxic nodules and thyroid neoplasms $[9,18,19]$. In this study the most common indications for thyroid surgeries were also toxic and non-toxic multi-nodular goiter followed by thyroid neoplasms and there was not any significant difference regarding the preoperative indications in patients at different age groups.

In recent years, with an advance in diagnostic methods, the incidence of thyroid nodules is increasing and FNAB is the main initial diagnostic test in evaluation of thyroid nodules [20, 21]. However, the diagnostic accuracy of FNAB in malignant thyroid nodules is controversial. Recently, Kavanagh et al. [22] reported that, although FNAB is a safe and reliable method for cytological assessment of thyroid nodules, older patients were more likely to have non-diagnostic samples. However, we did not determine any significant differences regarding the cytological diagnoses of FNAB in patients at different age groups. Chiu et al. [23] retrospectively reviewed 1040 consecutive primary thyroid operations and reported that 380 of those patients were having cytologically indeterminate thyroid nodules. Among those $66 \%$ had follicular neoplasm, 12\% had Hurthle cell neoplasm, $12 \%$ had papillary carcinoma and $7 \%$ had neoplasms with cellular atypia. In our study, although the number of patients with FNAB diagnosis of atypia with undefined significance was low (4.8\%), among those patients the most common postoperative diagnoses were nodular goutier, papillary carcinoma, and follicular adenoma.

In a recent study, Liu et al. [24] investigated the characteristics of thyroid carcinoma in time and reported that papillary thyroid carcinoma was the most common type counting $86.4 \%$ of all thyroid carcinomas. In our study we also determined that papillary 
carcinomas were the most common type accounting for $84.5 \%$ of all thyroid carcinomas in all decades. Nieman et al. [25] reported that patients with papillary thyroid cancer aged younger than 25 years of age or older than 75 years, exhibit higher rates of aggressive histopathologic features compared to patients aged between 25-75 years. However, we did not determine any significant differences between groups regarding outcomes of thyroid operations including patients with papillary carcinomas.

Substernal goiter may be regarded as a challenging indication for thyroid surgeons. In a recent study it was reported that among 1145 patients who underwent thyroid surgery, 60 (5.2\%) patients were having substernal goiter. In that study also, similar with our results, $88 \%$ of patients were female [26]. Moten et al. [27] reported that Substernal thyroidectomy patients were older compared with the non-substernal cases. In our study the ratio of substernal goiter was $7.9 \%$ and we determined that substernal goiter was significantly more common in patients in the 6th decade of their life.

\section{Limitations}

There are some limitations of this study that should be mentioned. This is a retrospective study based on hospital records and performed in a single center. The number of patients with complications was low and follow-up data was not present in all patients.

\section{CONCLUSION}

In conclusion, we determined that, there was not any significant difference regarding postoperative outcomes in patients operated for thyroid diseases who were in the different decades of their lives. We can suggest that, thyroid surgeries are as safe in elderly patients as in younger patients. Larger prospective studies are required to determine the effects of age on outcomes of thyroid surgeries.

\section{Authors' Contribution}

Study Conception: AÇ, ÇT; Study Design: AÇ, ÇT; Supervision: AÇ, ÇT; Funding: AÇ, ÇT; Materials: AÇ, ÇT; Data Collection and/or Processing: AÇ, ÇT; Statistical Analysis and/or Data Interpretation: AÇ, ÇT; Literature Review: AÇ, ÇT, NAI; Manuscript
Preparation: AÇ, ÇT and Critical Review: AÇ, ÇT.

\section{Ethics statement}

This study was designed as retrospective research, so that informed consent was obtained from all individual participants included in the study, but we have no ethical approval for this article. However, this article does not contain any studies with human participants or animals performed by any of the authors.

\section{Conflict of interest}

The authors disclosed no conflict of interest during the preparation or publication of this manuscript.

Authors declare that they have no conflict of interest.

\section{Financing}

The authors disclosed that they did not receive any grant during conduction or writing of this study.

\section{REFERENCES}

1. Ferlay J, Soerjomataram I, Dikshit R, Eser S, Mathers C, Rebelo $\mathrm{M}$, et al. Cancer incidence and mortality worldwide: sources, methods and major patterns in GLOBOCAN 2012. Int J Cancer 2015;136:E359-86.

2. Lee YS, Lee BJ, Hong HJ, Lee KD. Current trends of practical issues concerning micropapillary thyroid carcinoma: The Korean Society of Thyroid-Head and Neck Surgery. Medicine 2017;96:e8596.

3. Sun GH, DeMonner S, Davis MM. Epidemiological and economic trends in inpatient and outpatient thyroidectomy in the United States, 1996-2006. Thyroid 2013;23:727-33.

4. Cernea CR, Brandão LG, Hojaij FC, Carlucci DD, Montenegro FLM, Plopper C, et al. How to minimize complications in thyroid surgery? Auris Nasus Larynx 2010;37:1-5.

5. Narayanan S, Arumugam D, Mennona S, Wang M, Davidov $\mathrm{T}$, Trooskin SZ. An evaluation of postoperative complications and cost after short-stay thyroid operations. Ann Surg Oncol 2015;23:1440-5.

6. Shevchyk IV, Cobian BA, Martinez SR. Age-based disparities in the use of total thyroidectomy for papillary thyroid carcinoma. Clin Transl Oncol 2017;19:1253-9.

7. Haugen BR, Alexander EK, Bible KC, Doherty GM, Mandel SJ, Nikiforov YE, et al. 2015 American thyroid association management guidelines for adult patients with thyroid nodules and differentiated thyroid cancer: the American thyroid association guidelines task force on thyroid nodules and differentiated thyroid cancer. Thyroid 2016;26:1-133.

8. Molinari AS, Treiguer A, Gava, VG, Rojas JL, Evangelista PE, Gonçalves I, Treiguer A, Gava VG, et al. Thyroid surgery performed on an overnight basis: a 17 years of experience. Arch En- 
docrinol Metab 2015;59:434-40.

9. Isik A, Firat D, Yilmaz I, Peker K, Idiz O, Yilmaz B, et al. A survey of current approaches to thyroid nodules and thyroid operations. Int J Surg 2018;54:100-4.

10. Grubey JS, Raji Y, Duke WS, Terris DJ. Outpatient thyroidectomy is safe in the elderly and super-elderly. Laryngoscope 2018;128:290-4.

11. Kovačić I, Kovačić M. Surgical treatment of thyroid gland in elderly patients: our experiences. Acta Med Croatica 2016;70:185-90.

12. Diaconescu MR, Glod M, Costea I. Clinical features and surgical treatment of thyroid pathology in patients over 65 years. Chirurgia 2016;111:120-5.

13. Canonico S, Pellino G, Pameggiani D, Sciaudone G, Candilio G, De Fatico GS, et al. Thyroid surgery in the elderly: a comparative experience of 400 patients from an Italian university hospital. Int Surg 2014;99:523-7.

14. Papaleontiou M, Hughes DT, Guo C, Banerjee M, Haymart MR. Population-based assessment of complications following surgery for thyroid cancer. J Clin Endocrinol Metab 2017;102:2543-51.

15. Caulley L, Johnson-Obaseki S, Luo L, Javidnia H. Risk factors for postoperative complications in total thyroidectomy: a retrospective, risk-adjusted analysis from the National Surgical Quality Improvement Program. Medicine 2017;96:e5752.

16. Liu J, Sun W, Dong W, Wang Z, Zhang P, Zhang T, et al. Risk factors for post-thyroidectomy haemorrhage: a meta-analysis. Eur J Endocrinol 2017;176:591-602.

17. Puzziello A, Rosato L, Innaro N, Orlando G, Avenia N, Perigli G, et al. Hypocalcemia following thyroid surgery: incidence and risk factors. A longitudinal multicenter study comprising 2,631 patients. Endocrine 2014;47:537-42.

18. Liao S, Shindo M. Management of well-differentiated thyroid cancer. Otolaryngol Clin North Am 2012;45:1163-79.
19. Yano Y, Sugino K, Akaishi J, Uruno T, Okuwa K, Shibuya H, et al. Treatment of autonomously functioning thyroid nodules at a single institution: radioiodine therapy, surgery, and ethanol injection therapy. Ann Nucl Med 2011;25:749-54.

20. Gharib H, Papini E. Thyroid nodules: clinical importance, assessment, and treatment. Endocrinol Metab Clin North Am 2007;36:707-735.

21. Caleo A, Vigliar E, Vitale M, Crescenzo VD, Cinelli M, Carlomagno $\mathrm{C}$, et al. Cytological diagnosis of thyroid nodules in Hashimoto thyroiditis in elderly patients. BMC Surg 2013;13:S2S41.

22. Kavanagh J, McVeigh N, McCarthy E, Bennett K, Beddy P. Ultrasound-guided fine needle aspiration of thyroid nodules: factors affecting diagnostic outcomes and confounding variables. Acta Radiol 2017;58:301-6.

23. Chiu CG, Yao R, Chan SK, Strugnel SS, Bugis S, Irvine R, et al. Hemithyroidectomy is the preferred initial operative approach for an indeterminate fine needle aspiration biopsy diagnosis. Can J Surg 2012;55:191-8.

24. Liu X, Zhu L, Wang Z, Cui D, Chen H, Duan Y, et al. Evolutionary features of thyroid cancer in patients with thyroidectomies from 2008 to 2013 in China. Sci Rep 2016;22;6:28414.

25. Niemann AC, Reid AT, Smith J, James Hammond J, DeBolle AS, Wei I, et al. Association of patient age with high-risk pathologic features in papillary thyroid cancer. J Surg Res 2017;211:228-32.

26. Chávez Tostado KV, Velázquez-Fernandez D, Chapa M, Pantoja Millán JP, Salazar MS, Herrera MF. Substernal goiter: correlation between grade and surgical approach. Am Surg 2018;84:262-6.

27. Moten AS, Thibault DP, Willis AW, Willis AI. Demographics, disparities, and outcomes in substernal goiters in the United States. Am J Surg 2016;211:703-9. 